\title{
CARACTERÍSTICAS SOCIOECONÔMICAS DOS COMERCIANTES DE PLANTAS MEDICINAIS DE CURRAIS NOVOS/RN.
}

\author{
F.A.G. Rocha ${ }^{1,2}$, M.F.F. Araújo ${ }^{2}$, N.D.L. Costa ${ }^{2}$, R.P. Silva ${ }^{3}$, P.V.D.M. Queiroga ${ }^{3}$, L. A. Marciano ${ }^{1}$, E. D. M. Pontes ${ }^{1}$ e \\ J. A. B. Souza ${ }^{1}$ \\ ${ }^{1}$ Instituto Federal de Educação, Ciência e Tecnologia do Rio Grande do Norte - Campus Currais Novos \\ ${ }^{2}$ Programa Regional de Pós-Graduação em Desenvolvimento e Meio Ambiente (PRODEMA/UFRN) \\ ${ }^{3}$ Universidade Potiguar \\ angelo.gurgel@ifrn.edu.br -mag@cb.ufrn.br
}

Artigo submetido em junho/2013 e aceito em agosto/2013

\section{RESUMO}

As feiras livres são espaços dinâmicos, essenciais à integração socioeconômica entre comunidades, em especial nas cidades de pequeno porte. Dentre os produtos disponíveis, encontram-se as plantas medicinais, importantes recursos terapêuticos para a parcela mais carente da população. Objetivamos determinar as características socioeconômicas e culturais dos comerciantes de plantas medicinais em
Currais Novos/RN. A atividade é predominantemente exercida por homens, de baixo poder aquisitivo e escolaridade. O comércio de plantas medicinais é a principal fonte de renda para $67,0 \%$ dos entrevistados e os dados apontam tendência à extinção da atividade na feira livre de Currais Novos.

PALAVRAS-CHAVE: Etnobotânica, medicina tradicional, fitoterapia, feira livre, gestão cultural.

\section{SOCIO-ECONOMIC CHARACTERISTICS OF TRADERS OF MEDICINAL PLANTS OF CURRAIS NOVOS/RN.}

\section{ABSTRACT}

The street fairs are dynamic spaces, essential for socioeconomic integration between communities, especially in small towns. Among the products available are medicinal plants, important therapeutic resources for the poorest portion of the population. We aimed to determine the socioeconomic and cultural characteristics of the herbalist in Currais Novos/RN. The activity is predominantly practiced by men, low income and education. The trade of medicinal plants is the main source of income for $67.0 \%$ of the respondents and the data points tend to the extinction of the activity at the street fair of Currais Novos.

KEYWORDS: Ethnobotany, traditional medicine, phytotherapy, street fair, cultural management. 


\section{CARACTERÍSTICAS SOCIOECONÔMICAS DOS COMERCIANTES DE PLANTAS MEDICINAIS DE CURRAIS NOVOS/RN.}

\section{INTRODUÇÃO}

Tradicionalmente, as feiras livres constituem importantes fontes para a aquisição de plantas medicinais pelos usuários. Em tais espaços são comercializadas espécies nativas e exóticas, fruto do cultivo, importação e, principalmente, do extrativismo praticado no entorno da comunidade. Comercializadas in natura ou processadas de forma artesanal, as plantas medicinais são apresentadas na forma de órgãos íntegros ou não, em geral desidratados. É comum que sejam comercializados preparos tradicionais os quais, em dependência de sua composição, recebem denominações diversas, tais como lambedor, garrafada e tintura, dentre outros. As indicações e aplicações são variadas, abrangendo desde o tratamento e prevenção de doenças até o uso em rituais de caráter místico-religioso (ABBA et. al., 2009; ALVES; SILVA; ALVES, 2008; IDU; EHARBOR; IDELE, 2011; MONTEIRO et al., 2010).

Embora não seja possível determinar de forma precisa a origem da feira livre, sabe-se que durante a Idade Média, no início do Sec. IX, as feiras espalharam-se em números crescentes ao longo de toda a Europa. No Brasil, por sua vez, o seu advento remonta ao ano de 1841, quando surgiram como uma solução para os problemas relacionados ao abastecimento regional de produtos (GORBERT; FRIDMAN, 2003; PIRENNE, 1956).

A feira é um espaço dinâmico, onde se relacionam direta e indiretamente indivíduos de diversas origens, classes sociais, idades e interesses, em uma rede de relações sociais na qual a cooperação, a competição e o comércio se entremeiam. Por sua dinâmica é, por excelência, um espaço de integração entre comunidades, principalmente no norte e nordeste do Brasil (ALMEIDA; PENA, 2011; MINNAERT; FREITAS, 2010; SATO, 2007).

Essencialmente polarizando as atividades comerciais de produtores locais e oriundos de municípios circunvizinhos, a feira livre favorece o intercâmbio cultural e os fluxos de capitais. Nas cidades interioranas, são importantes mecanismos de geração de renda através da comercialização a varejo. Pela concentração da oferta variada de produtos em múltiplos pontos de venda, possibilita aos consumidores a comparação simultânea entre preços e produtos. Tal dinâmica, implícita à livre concorrência, impacta de forma positiva a quantidade, a qualidade e o custo das mercadorias disponíveis, favorecendo o consumidor. O impacto econômico sobre os elementos que a utilizam como espaço de negociação é claro, tanto entre os comerciantes cuja atividade pode ser a única fonte a compor a renda familiar, como também entre os consumidores, que nela encontram a oportunidade de adquirir alimentos e outros produtos a preços acessíveis (ALMEIDA et al., 2011).

Apesar da sua ampla diversidade, as feiras livres compartilham características que as qualificam como pertencentes ao circuito inferior da economia de suas cidades-sede. Os aspectos mais importantes neste contexto são: a utilização de baixa tecnologia e baixo nível de conhecimento técnico; a presença do trabalho intensivo essencialmente voltado à subsistência; vínculos de trabalho e proteção social precários; atividade comercial essencialmente voltada ao atendimento das camadas sociais médias e populares locais (SANTOS, 2004; SATO, 2007).

Dado o seu caráter polarizador, as feiras livres concentram importantes informações de cunho etnobotânico, disponibilizando à população os insumos requeridos nas práticas terapêuticas tradicionais. Dentre estes, destacam-se pela sua importância cultural e alta aceitabilidade as plantas medicinais e preparos derivados, oferecidos aos usuários como soluções 
terapêuticas de baixo custo (ARAÚJO et al., 2009; LIMA; COELHO-FERREIRA; OLIVEIRA, 2011; PAULINO et al., 2012; ROCHA et al., 2010; ROCHA et al., 2012).

A comercialização de plantas medicinais em feiras livres pode representar a única alternativa de tratamento disponível às comunidades carentes. Contudo, está sujeita à condições de higiene precárias que representam risco à saúde humana. Tal fato deriva da compreensão deficiente que os feirantes possuem de relações abstratas complexas tais como a existente entre a falta de higiene em sua prática diária, a introdução de patógenos nos produtos e o desenvolvimento de doenças nos consumidores. Como resultado, os produtos comercializados podem representar com frequência, risco à saúde da população (ALMEIDA; PENA, 2011; IDU; EHARBOR; IDELE, 2011; MINNAERT; FREITAS, 2010; ROCHA et al., 2010; MEDEIROS et al., 2012; STEVIC, et al., 2012).

Apesar da importância socioeconômica e sanitária da comercialização de plantas medicinais em feiras livres, são poucos os grupos que se dedicam à compreensão do fenômeno, incluindo os aspectos relacionados à caracterização socioeconômica e cultural dos comerciantes. Tal deficiência dificulta o desenvolvimento de políticas públicas voltadas à preservação da atividade, capacitação dos comerciantes, melhoria nas suas condições de trabalho e na qualidade dos produtos ofertados aos consumidores.

Tendo como base a insuficiência de dados relacionados ao comércio informal de plantas medicinais em feiras livres do Rio Grande do Norte, o Programa de Pós-Graduação em Desenvolvimento e Meio Ambiente (PRODEMA/UFRN) em parceira com o Instituto Federal de Educação, Ciência e Tecnologia do Rio Grande do Norte (IFRN) desenvolvem esforços no sentido de caracterizar e compreender as peculiaridades próprias à atividade na região Seridó/RN. Neste contexto, o presente estudo objetivou a caracterização socioeconômica dos comerciantes de plantas medicinais atuantes na feira livre de Currais Novos (RN), contribuindo para a compreensão da atividade e de sua importância para as comunidades locais.

\section{METODOLOGIA}

O estudo foi aprovado pelo Comitê de Ética da Universidade Federal do Rio Grande do Norte (UFRN), através do parecer $n^{\circ} 98.400 / 2012$.

Neste trabalho, adotou-se a definição de "feira livre" utilizada pelo Ministério do Desenvolvimento Social e Combate à Fome. Neste contexto, a feira livre é definida como um equipamento comercial de periodicidade, localização e formato variáveis, cujo esquema de comercialização difere do adotado em estabelecimentos varejistas do comércio formal, tais como supermercados, sacolões e mercados públicos (BRASIL, 2007).

A feira livre selecionada para o presente estudo situa-se no nordeste brasileiro, no Estado do Rio Grande do Norte, mesorregião Central Potiguar, microrregião Seridó Oriental, zona urbana de Currais Novos (Figura 1). O município localiza-se sob as coordenadas $6^{\circ} 15^{\prime} 39,6^{\prime \prime}$ de latitude Sul e $36^{\circ} 30^{\prime} 54,0^{\prime \prime}$ de longitude Oeste, distando cerca de $192 \mathrm{Km}$ da capital do estado, Natal (BRASIL, 2005).

A escolha de Currais Novos para a realização do estudo deveu-se ao fato do mesmo ser considerado pelo Instituto de Desenvolvimento Sustentável e Meio Ambiente do Rio Grande do Norte (IDEMA) como Centro Polarizador da Zona Homogênea que nomeia. Desse modo, sua feira livre polariza atividades comerciais de municípios vizinhos e de comunidades do entorno. Adicionalmente, segundo dados do Censo 2010, Currais Novos é o município mais populoso da microrregião Seridó Oriental com 42.652 habitantes, correspondendo a aproximadamente 1,3\% 
da população total do estado (INSTITUTO BRASILEIRO DE GEOGRAFIA E ESTATÍSTICA, 2013a; IDEMA, 2009).

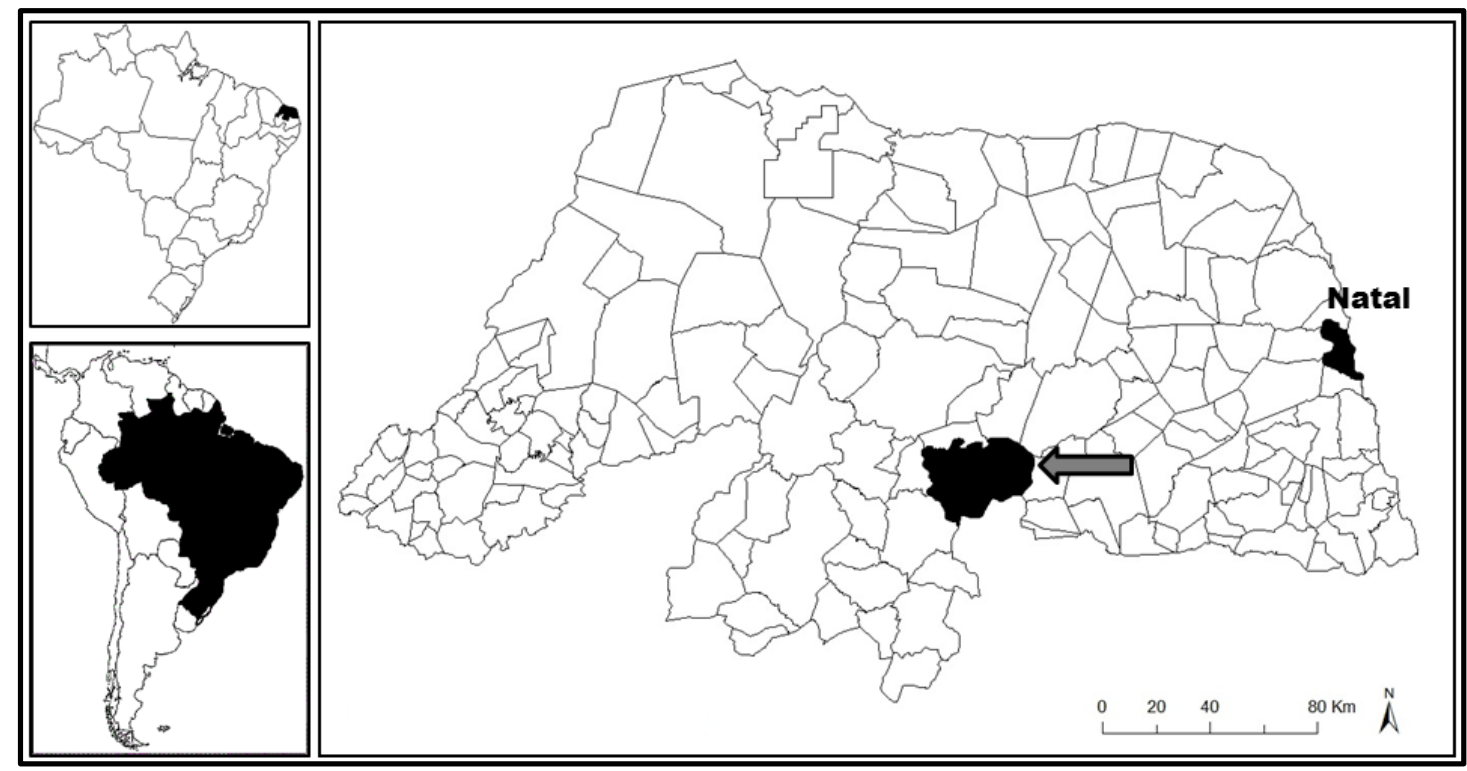

FONTE: adaptado a partir das fontes cartográficas do IBGE (INSTITUTO BRASILEIRO DE GEOGRAFIA E ESTATÍSTICA, 2013b).

Figura 1 - Localização geográfica do município de Currais Novos/RN, indicado pela seta.

O presente trabalho se constitui em um Estudo de Caso. Dado o reduzido número de elementos constituintes do Universo estudado, utilizou-se amostragem não probabilística, objetivando incluir o maior número possível de indivíduos. Desse modo, para a seleção da amostra, incluímos no presente estudo todos os comerciantes que cumpriram com os seguintes critérios de inclusão: praticar a comercialização de plantas medicinais de forma isolada ou em conjunto com outros produtos; participar assiduamente da feira livre a pelo menos um ano e concordar integralmente com as condições expostas no nosso Termo de Consentimento Livre e Esclarecido - TCLE. Os critérios de exclusão considerados foram: não comercializar plantas medicinas, fazê-lo de forma esporádica ou a menos de um ano e não concordar integralmente com o nosso TCLE.

A coleta de dados in loco ocorreu no período de fevereiro a março de 2013 , através de entrevista conduzida com uso de formulário estruturado, composto por 21 questões de múltipla escolha, elaborado com base nos moldes adotados pelo IBGE (INSTITUTO BRASILEIRO DE GEOGRAFIA E ESTATÍSTICA, 2013a). Foram contemplados aspectos como: gênero, cor, religião, idade, grau de escolaridade, renda familiar e tempo de atuação no comércio de plantas medicinais e seus derivados. Visando a digitação e o processamento dos dados, as alternativas de cada questão foram codificadas com emprego de valores numéricos entre 0 e 2.000, conforme 0 caso. Todos os dados obtidos em campo foram armazenados e processados com uso do Software Statistica (STATSOFT, 2010). Dado o número reduzido de comerciantes na área estudada, foram utilizadas ferramentas descritivas para a análise e expressão dos resultados.

\section{RESULTADOS E DISCUSSÃO}

Em relação ao número total de comerciantes de plantas medicinais existente na área da feira livre estudada, constatou-se a presença de seis pontos de comercialização do produto em 
questão, com $100,0 \%$ de concordância em sua participação no estudo. Do total, $66,7 \%$ comercializavam apenas plantas medicinais e seus derivados, enquanto 33,3\% o fazia em conjunto com outros produtos de natureza diversa, coletivamente denominados pelos entrevistados como "mangai". Tal denominação abrange uma gama variável de produtos, consistindo em utensílios domésticos, ferragens, miudezas, produtos confeccionados com couro, containers plásticos, dentre outros (Figura 2).

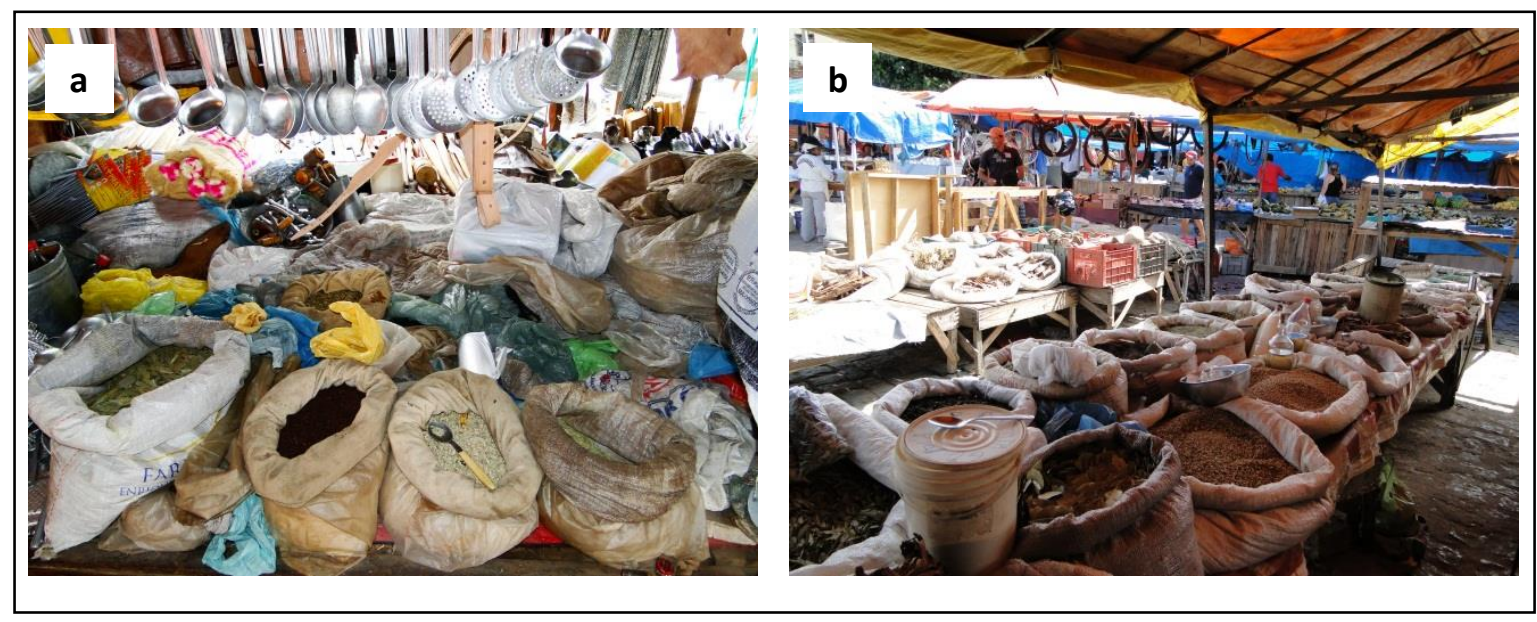

FONTE: arquivo pessoal do autor.

Figura 2 - Pontos de comercialização de plantas medicinais típicos; a) comercialização conjunta com produtos de outra natureza ("mangai"); b) Comercialização exclusiva de plantas medicinais e prebaros tradicionais.

Dentre os que comercializavam plantas medicinais conjuntamente com os produtos diversos anteriormente descritos ("mangai"), 17,0\% declararam ter reduzido de forma significativa a disponibilidade de espécies vegetais, de modo que a venda do produto passou a ser uma atividade residual dentro de sua prática diária. Observou-se a comercialização de plantas medicinais nativas e exóticas, in natura ou dessecadas, na forma de órgãos íntegros (folhas, raízes, frutos), fragmentados (cascas, flores...) ou rasurados (rizomas, tubérculos). Igualmente, estavam disponíveis extratos diversos (óleos) e preparos tradicionais (lambedores, garrafadas), destinados ao uso terapêutico ou para finalidades místico-religiosas.

Dos seis comerciantes entrevistados $83,3 \%$ declararam residir na zona urbana de Currais Novos/RN, enquanto $16,7 \%$ no município vizinho de Lagoa Nova/RN, também em sua zona urbana. Nenhum dos participantes declarou residência na zona rural, contrariamente ao observado por Dantas e Guimarães (2006) na Paraíba, que relataram que, entre seus entrevistados, 25,6\% declararam morar na zona rural da área estudada.

Todos os entrevistados possuíam apenas uma barraca na feira livre de Currais Novos, sendo que $66,6 \%$ atuavam em todos os dias da semana, e 33,0\% apenas em dias específicos, de maior movimento. Embora $83,0 \%$ residam no município, $67,0 \%$ do total exercem a atividade em feiras livres de cidades circunvizinhas, como forma de incrementar a arrecadação mensal.

Quanto à cor ou raça $83,3 \%$ dos entrevistados declararam-se pardos, enquanto $16,7 \%$, brancos. Rocha et al. (2012) em estudo desenvolvido no município vizinho, Lagoa Nova, relataram uma composição racial diferente entre os comerciantes de plantas medicinais, com frequências equivalentes a $40,0 \%$ de negros, $40,0 \%$ de brancos e $20,0 \%$ de pardos. Embora divergentes, os dados obtidos em ambos os estudos são concordantes com o Censo 2010, no qual se constatou que na distribuição relativa por cor ou raça nos ambientes urbanos 
predominam indivíduos brancos, negros e pardos. Em contraste, Dantas e Guimarães (2006) em seu estudo realizado em áreas metropolitanas do norte e nordeste brasileiros constataram o predomínio de caboclos (55,8\%), seguido de brancos (30,2\%), negros e índios (ambos com 7,0\%). Os dados descritos em todos os estudos citados refletem os padrões históricos de ocupação e dinâmica econômica regional, conforme explicitado pelo IBGE no Censo 2010 (INSTITUTO BRASILEIRO DE GEOGRAFIA E ESTATÍSTICA, 2013a).

No estudo hora apresentado, 100,0\% dos entrevistados declararam-se católicos. A predominância da religião católica também foi observada por Dantas e Guimarães (2006) nas cidades de Campina Grande/PB, João Pessoa/PB, Teresina/PI, São Luís/MA e Belém/PA, com frequência média equivalente a 86,0 \%. Por sua vez, Araújo et al (2009) relataram frequência de 41,3 \% de católicos em Maceió/AL. Os mesmos autores também observaram a participação de evangélicos, espíritas kardecistas, umbandistas e adeptos de outras religiões no comércio de plantas medicinais.

Embora em nosso estudo todos os entrevistados tenham se declarado católicos, em 100,0 $\%$ dos casos afirmaram conhecer o fato de que parte dos produtos que vendiam encontrava aplicações místico-religiosas. Dentre estas, a cura de males "espirituais" (referidos pelos comerciantes como "mau olhado" e "quebranto"), o uso para a realização de "simpatias" e de rituais diversos, pertencentes a outros sistemas de crenças, diferentes dos seus. Tal constatação é consistente com o que foi denominado pela Antropologia Clássica como "pensamento mágicoreligioso". Neste contexto, a utilização de plantas medicinais envolve concepções que englobam abordagens filosóficas sobre a vida, enfermidade e morte que nem sempre são equiparáveis aos conceitos modernos ocidentais (LUZ, 2005).

Quanto ao gênero, verificou-se que $83,0 \%$ dos entrevistados pertenciam ao sexo masculino. $O$ predomínio dos homens na atividade também foi observado por Alves, Silva e Alves (2008) nas cidades de Teresina/PI (63,0\%), São Luís/MA (62,0\%) e Belém/PA (56,0\%) e por Rocha et al. (2012), na cidade de Lagoa Nova/RN onde os autores constataram frequência equivalente a $60,0 \%$. Dantas e Guimarães (2006), por sua vez, registraram na cidade de Campina Grande/PB uma distribuição mais igualitária, com parcelas correspondentes a $51,2 \%$ de homens e $48,8 \%$ de mulheres.

A idade média dos entrevistados foi de 63 anos, com mínimo de 32 e máximo de 82 anos (Figura 3), o que é semelhante aos resultados obtidos por Dantas e Guimarães (2006) em Campina Grande, onde 53,6\% dos entrevistados possuíam idade igual ou superior a 50 anos.

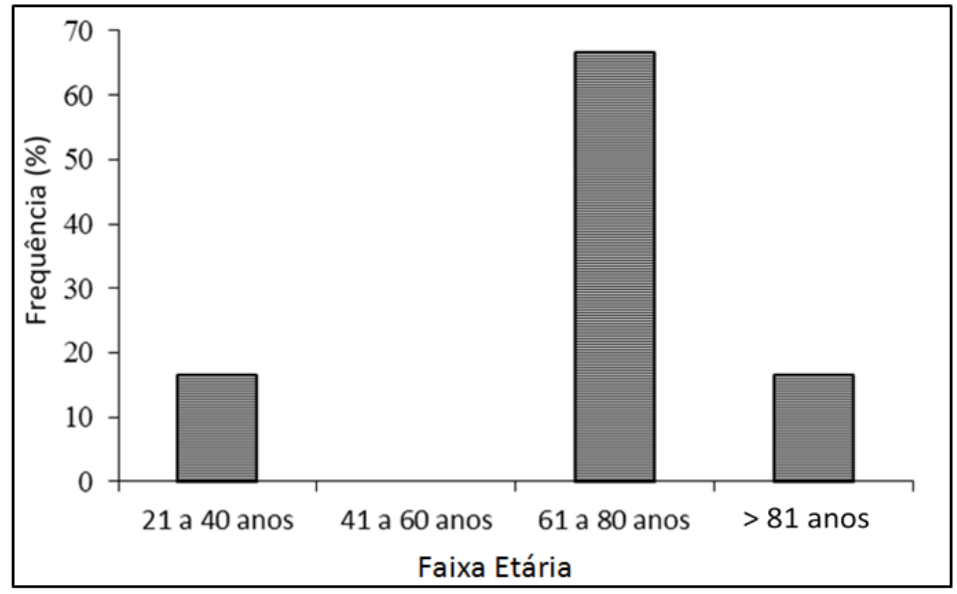

FONTE: dados do autor.

Figura 3 - Distribuição por faixa etária dos comerciantes de plantas medicinais atuantes na feira livre de Currais novos, RN. 
Conforme Alves, Silva e Alves (2008) o predomínio das faixas etárias mais elevadas nas atividades relacionadas à cadeia produtiva das plantas medicinais já é esperado, uma vez que o conhecimento acerca das suas propriedades curativas tende a se concentrar em pessoas com idade mais elevada.

Durante as entrevistas, $100,0 \%$ dos comerciantes afirmou atuar no ramo há mais de 20 anos. Um dos entrevistados declarou estar envolvido com a atividade desde criança, acompanhando os pais. A permanência no comércio de plantas medicinais por período superior a vinte anos também foi relatada por Alves, Silva e Alves (2008) nas cidades de João Pessoa/PB $(87,0 \%)$, Campina Grande/PB $(50,0 \%)$ e Belém/PA $(48,0 \%)$. Contudo, nas cidades de São Luíz/MA e Teresina/PI, os mesmos autores encontraram frequências maiores nas faixas compreendendo de 6 a 10 anos de atuação $(33,0 \%)$ e de 11 a 20 anos de atuação $(43,0 \%)$, respectivamente. Os autores constataram a presença de indivíduos que exercem a atividade há menos de cinco anos apenas nas cidades de São Luiz/MA $(19,0 \%)$ e Belém/PA Guimarães (2006) em estudo desenvolvido em Campina > 81 anos Grande/PB, relataram que $88,4 \%$ atuavam na atividade há mais de cinco anos com média equivalente a 17 anos, enquanto que $11,6 \%$ o faziam há período inferior a cinco anos. A permanência dos indivíduos na atividade por período longo pode ser interpretado como um indício da importância que a venda dos produtos tradicionais tem para o sustento de suas famílias.

O tempo de atuação no comércio de plantas medicinais em nossas observações tem uma correlação direta com a idade dos entrevistados, refletindo mais uma vez as afirmações de Alves, Silva e Alves (2008) acerca da concentração do conhecimento etnobotânico em indivíduos mais idosos e, consequentemente, com maior tempo de atuação no ramo, refletindo o caráter tradicional do comércio de plantas medicinais. Quanto à escolaridade (Figura 4), nenhum dos entrevistados declarou ter concluído o ensino médio, com maiores frequências observadas nos estratos "nível fundamental incompleto" e "nenhum", concordando com Dantas e Guimarães (2006) que relataram a frequência de $69,8 \%$ nos mesmos níveis de escolaridade.

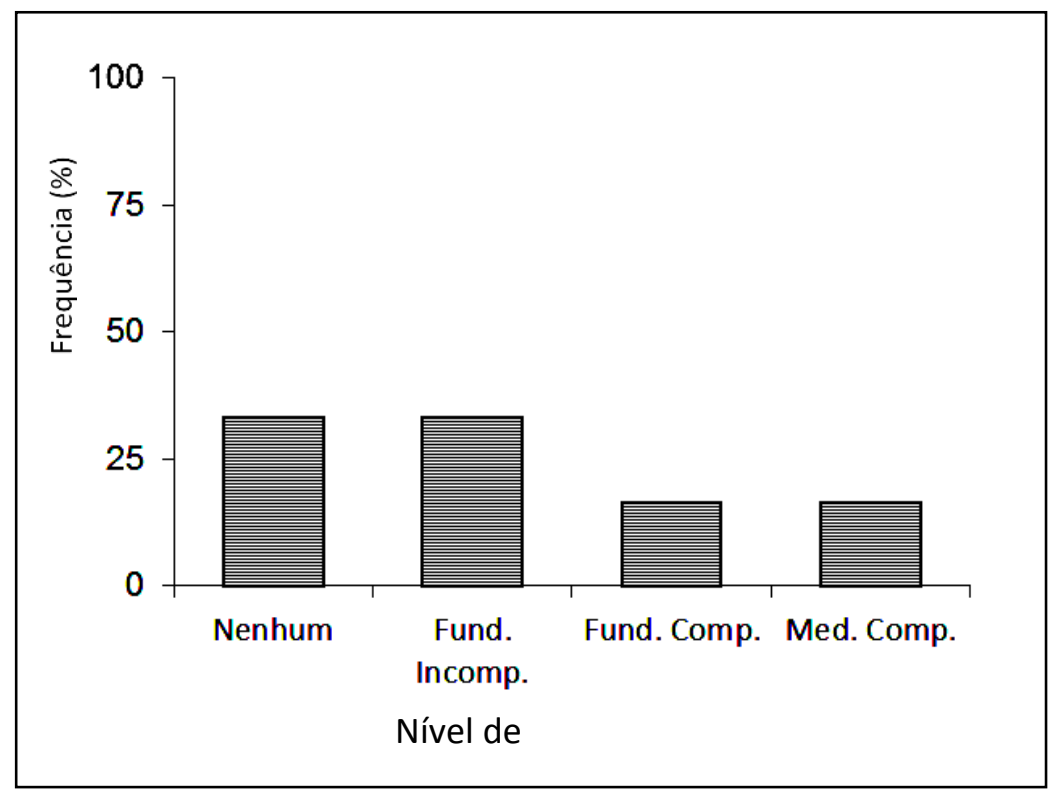

FONTE: dados do autor.

Figura 4 - Distribuição dos comerciantes de plantas medicinais atuantes na feira livre de Currais Novos/RN conforme o nível de Escolaridade. 
Araújo et al. (2009) por sua vez constataram em Maceió/AL, que 8,7\% do comerciantes possuía o ensino fundamental, $19,6 \%$ o ensino médio e $28,3 \%$ eram analfabetos ou semianalfabetos. Estudo desenvolvido por Rocha et al. (2012) no município vizinho de Lagoa Nova/RN constatou que $60,0 \%$ dos entrevistados declararam não ter concluído nenhum nível de escolaridade, enquanto a parcela de $20,0 \%$ possuía o nível médio incompleto. 0 mesmo estudo relata que $20,0 \%$ dos entrevistados afirmaram estar cursando o nível superior.

O baixo nível de escolaridade observado entre os feirantes impacta diretamente a qualidade dos produtos que comercializam. Segundo Almeida e Pena (2011), o conhecimento científico fornece "instrumentos teórico-metodológicos que nos permitem enxergar além dos sentidos". Os feirantes, por suas condições socioeconômicas, podem não ter tido acesso adequado às ferramentas e oportunidades para transcender os sentidos e perceber o mundo através de um olhar mais criterioso e respaldado por conceitos complexos como a relação entre baixas condições de higiene em seu local de trabalho, a presença de patógenos e a transmissão de doenças. Tal conjunção de fatores estabelece na prática diária a aplicação de rotinas e estrutura física inadequadas do ponto de vista higiênico- sanitário, favorecendo a contaminação e proliferação microbiana nas plantas medicinais e seus derivados, incluindo-se neste contexto microrganismos patogênicos para humanos. Reconhecendo o risco potencial advindo da presença de microbiota indesejável em plantas medicinais, a Organização Mundial da Saúde aponta a veiculação de patógenos neste tipo de material como um problema de saúde pública (WORLD HEALHT ORGANIZATION, 2007).

No caso específico da feira livre de Currais Novos/RN, Rocha et al. (2008), Rocha et al. (2010) e Medeiros et al. (2012) determinaram em amostras de plantas medicinais de alta aceitação popular utilizadas no preparo de chás, densidades de microrganismos deteriorantes e/ou patogênicos superiores aos limites estabelecidos pela OMS (bactérias aeróbias mesófilas, $10^{7} \mathrm{UFC} / \mathrm{g}$; Escherichia coli, $10 \mathrm{UFC} / \mathrm{g}$; Bolores e leveduras, $10^{4} \mathrm{UFC} / \mathrm{g}$ ) e pela Agência Nacional de Vigilância Sanitária (bactérias aeróbias mesófilas, $10^{7} \mathrm{UFC} / \mathrm{g}$; Escherichia coli, $10^{2} \mathrm{UFC} / \mathrm{g}$; Bolores e leveduras, $10^{4} \mathrm{UFC} / \mathrm{g}$ ). Nas análises, foram constatadas frequências de reprovação de até $100,0 \%$ das amostras analisadas, consequência direta das condições de higiene inadequadas presentes nos pontos de venda (BRASIL, 2010; WORLD HEALTH ORGANIZATION, 2007).

A ingestão por humanos de produtos de qualidade microbiológica inadequada pode promover intoxicações, infecções ou toxinfecções de gravidade variável, podendo resultar em óbito. O risco à saúde é amplificado no caso de crianças e idosos, faixas etárias mais vulneráveis, nas quais o uso de chás é frequente. Adicionalmente, devemos considerar que a presença de altas densidades de microrganismos em uma planta medicinal pode promover a degradação enzimática de um ou mais princípios ativos, o que potencialmente pode resultar em toxicidade, redução ou perda da ação terapêutica esperada (PLESIS-STOMAN et al., 2009; SUREKHA et al., 2011).

Em 100,0\% dos casos, os comerciantes afirmaram ter optado pela atuação na feira livre como alternativa à ausência de outras oportunidades profissionais em decorrência do baixo nível de escolaridade que possuíam, fato também observado por Alves, Silva e Alves (2008) em áreas metropolitanas do norte e nordeste brasileiros. A predominância da baixa escolaridade observada entre os entrevistados, portanto, tem relação direta com as restrições de acesso ao mercado de trabalho impostas às pessoas com pouca ou nenhuma educação formal. Neste contexto, sua inserção em atividades informais como a comercialização de plantas medicinais em feiras livres, apresenta-se como uma alternativa viável de geração de renda já que não depende 
da instrução formal, mas antes disso, de conhecimentos tradicionais vigentes em suas comunidades de origem.

Para $66,7 \%$ dos entrevistados, a comercialização de plantas medicinais representa a sua principal fonte de renda. Em $100,0 \%$ dos casos, foi relatada renda familiar na faixa de um a três salários mínimos, bem como a existência de fontes de renda complementares à atividade. Em $83,0 \%$ dos relatos, a renda extra é proveniente de aposentadorias e benefícios, o que é condizente com a idade média dos indivíduos. Nossas observações são compatíveis com as realizadas por Araújo et al. (2010) na cidade de Maceió/AL, na qual os autores constataram renda familiar similar entre seus entrevistados.

Em relação ao total bruto arrecadado mensalmente, $66,7 \%$ dos entrevistados declararam não conhecer o valor total. Os 33,3\% restantes declararam arrecadação bruta mensal situada na faixa entre 1,1 a 3 salários mínimos (Figura 5).

Quanto ao lucro mensal obtido com a atividade, $66,6 \%$ declarou não calcular o montante, enquanto $16,7 \%$ relatou lucro mensal situado na faixa entre 1,1 a 3 salários mínimos. Os $16,7 \%$ restantes declararam obter lucro mensal inferior a um salário mínimo. Dentre os entrevistados que afirmaram não conhecer sua arrecadação bruta nem sua margem de lucro, 33,3\% relataram já ter tido a necessidade de recorrer a empréstimos para financiar a aquisição de mercadorias e manter a viabilidade do negócio.

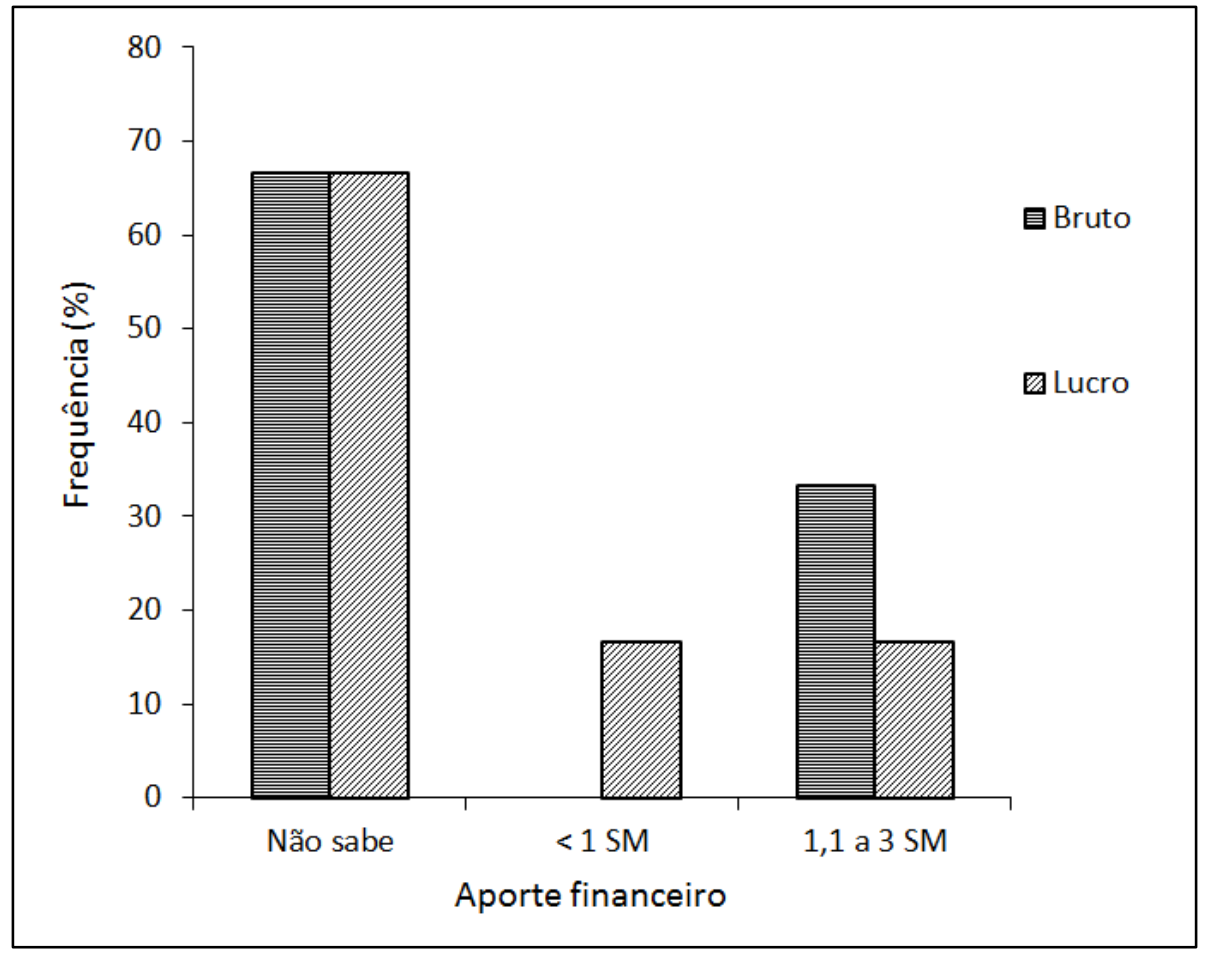

FONTE: dados do autor.

Figura 5 - Total bruto arrecadado e margem de lucro obtidos mensalmente pelos comerciantes de plantas medicinais estabelecidos na feira livre de Currais Novos/RN.

Em 100,0\% dos pontos de comercialização estudados, inexistiam os procedimentos relacionados ao registro das vendas e ao controle de estoque das mercadorias. A ausência de tais dados retrata o despreparo administrativo dos comerciantes e gera obstáculos na elaboração de um adequado planejamento financeiro a médio e longo prazo, necessário à sustentabilidade e ampliação do seu negócio. 
Todos os entrevistados relataram não efetuar a coleta das plantas que comercializavam, adquirindo-as a partir de terceiros: as espécies nativas da caatinga eram fornecidas por raizeiros residentes nos municípios de Currais Novos e Lagoa Nova, que desenvolviam a atividade extrativista no entorno das cidades citadas e no estado vizinho, a Paraíba. Espécies exóticas como cravo da índia (Syzygium aromaticum), boldo do Chile (Peumus boldus) e noz moscada (Myristica fragrans) por sua vez, eram adquiridas no comércio atacadista da Paraíba, a partir de onde eram importadas de São Paulo (Figura 6). Nenhum dos comerciantes afirmou cultivar as plantas que comercializava. Alves, Silva e Alves (2008) verificaram padrão semelhante nas cidades de Campina Grande/PB, João Pessoa/PB, São Luis/MA, Teresina/PI e Belém/PA. Rocha et al. (2012), por sua vez, relatam o mesmo fato no município de Lagoa Nova/RN, no qual as espécies comercializadas também eram adquiridas a partir de terceiros.

Cinquenta por cento dos entrevistados na feira livre de Currais Novos afirmaram fornecer regularmente espécies medicinais e condimentares para uma pequena empresa local, que efetuava o seu fracionamento, embalagem e rotulagem, sem nenhum processamento adicional. Posteriormente, o produto fracionado e embalado era revendido ao comércio varejista da cidade e de municípios situados nas microrregiões Seridó Oriental e Ocidental (Figura 6).

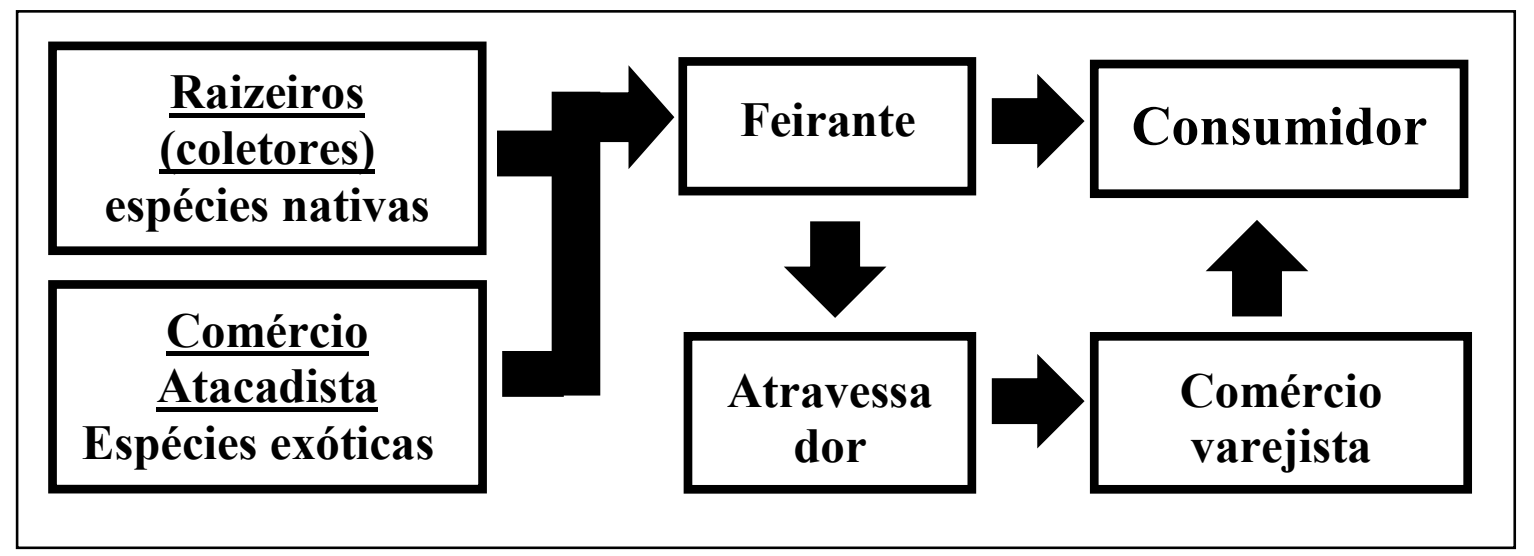

FONTE: dados do pesquisador.

Figura 6 - Elementos envolvidos na comercialização de plantas medicinais em Currais Novos/RN e respectivo fluxo de mercadorias.

O acondicionamento e rotulagem praticados agregam valor ao produto, possibilitando-o atingir um público consumidor de poder aquisitivo mais elevado, que normalmente recorre ao comércio formal para a aquisição dos produtos que utiliza. Neste contexto, caso houvesse capacitação e investimentos adequados, os próprios feirantes poderiam fornecer seus produtos diretamente aos supermercados da região, passando a atuar em um nicho de mercado até então restrito, aumentando sua arrecadação mensal.

Contudo, conforme anteriormente exposto, o consumo de plantas medicinais oriundas da feira livre de Currais Novos representa risco à saúde humana (ROCHA et al. 2008; ROCHA et al., 2010; MEDEIROS et al., 2012). Uma vez que o produto fracionado originário da feira não passava por nenhum processo de descontaminação, sendo, posteriormente vendido em supermercados da região, o risco à saúde anteriormente restrito aos consumidores da feira livre atinge um público consumidor significativamente maior. Com base nisto, qualquer estratégia de ampliação de mercado dos produtos da medicina tradicional comercializados pelos indivíduos abrangidos neste estudo, deve contemplar o seu treinamento em Boas Práticas, visando à segurança alimentar dos consumidores. 
A parcela de $83,3 \%$ dos entrevistados declarou ter iniciado o negócio por conta própria, sendo que apenas $16,7 \%$ declararam tê-lo herdado de avós ou pais. Sessenta e sete por cento dos feirantes afirmaram que seus descendentes não pretendem continuar na atividade. Em todos os casos, os entrevistados afirmaram que seus filhos e netos estão cursando ou concluíram os níveis de formação básica ou superior. Em $67,0 \%$ dos casos, os descendentes já possuem vínculos empregatícios no mercado formal de trabalho. Tais dados associados à observação do desinteresse das novas gerações em permanecer no negócio, apontam para a redução progressiva do comércio de plantas medicinais na feira livre de Currais Novos, RN. Mantida a tendência atual, o risco de extinção da atividade na área estudada é significativo.

As feiras livres constituem espaço de expressão cultural de um povo, em especial no tocante ao seu patrimônio etnobotânico (ARJONA; MONTEZUMA; SILVA, 2007). A extinção da atividade, portanto, ameaça a preservação de um número inestimável de informações acerca de novas fontes potenciais para o desenvolvimento fármacos, da exploração e sustentabilidade da atividade extrativista, dentre outras. As conseqüências negativas decorrentes da extinção do comércio informal de plantas medicinais sobre a saúde da população também devem ser consideradas, tendo em vista a alta aceitação do recurso pelos consumidores, bem como a sua eficácia terapêutica, em muitos casos comprovada.

O impacto econômico resultante do desaparecimento da comercialização de plantas medicinais também deve ser encarado de forma cuidadosa, já que conforme os dados obtidos, a atividade representa fonte indispensável de renda para as famílias envolvidas. Sua extinção, portanto, pode resultar em ainda mais exclusão social. A atividade também se mostra relevante economicamente do ponto de vista dos consumidores: segundo Alves, Silva e Alves (2008) a utilização de plantas medicinais pode representar para as famílias de baixa renda, uma redução significativa nos custos médicos, em especial para aquelas que contam com crianças e idosos entre seus integrantes.

Diante dos dados expostos e discutidos, torna-se explícita a necessidade do desenvolvimento imediato de esforços no sentido de preservar a comercialização de plantas medicinais em feiras livres. Contudo, é imperativo que sejam realizadas melhorias nas suas instalações físicas, bem como o desenvolvimento de ações educativas voltadas à capacitação dos feirantes na aplicação de rotinas de Boas Práticas em seus pontos de venda. Tais alterações resultariam em melhorias nas condições de trabalho presentes e na qualidade dos produtos oferecidos, tornando a atividade mais atraente tanto para as novas gerações, quanto para os usuários das plantas medicinais e preparos tradicionais delas derivados.

\section{CONCLUSÃO}

Os dados encontrados permitiram concluir que a comercialização informal de plantas medicinais na feira livre de Currais Novos é uma atividade exercida predominantemente por indivíduos do sexo masculino, de baixo poder aquisitivo e escolaridade. Embora fundamental na composição de sua renda familiar, inexistem por parte dos comerciantes, controles financeiro e administrativo adequados, o que dificulta o planejamento econômico a médio e a longo prazo. Observou-se uma tendência de diminuição progressiva da atividade, com risco significativo da sua extinção na área estudada.

É urgente que sejam desenvolvidas políticas públicas voltadas tanto à preservação da atividade de comércio de plantas medicinais brutas e preparos tradicionais em feiras livres, quanto ao estabelecimento de parâmetros de qualidade para o material disponível ao consumidor nestes locais. Adicionalmente, ao poder público cabem as responsabilidades de 
fornecer as estruturas físicas e logísticas necessárias e de exercer a fiscalização adequada dos produtos ofertados ao consumidor, através dos órgãos competentes.

Também se faz necessário que sejam empregados esforços no desenvolvimento de novos estudos sobre o tema e de ações educativas voltadas à aplicação de rotinas de Boas Práticas em todas as fases da cadeia produtiva das plantas medicinais, reduzindo os riscos à saúde da população.

\section{REFERÊNCIAS BIBLIOGRÁFICAS}

1. ABBA, D. et al. Contamination of herbal medicinal products marketed in Kaduna metropolis with selected pathogenic bacteria. African Journal of Traditional, Complementary and Alternative Medicines, v. 6, n. 1, p. 70 -77, 2009.

2. ALMEIDA, M. D.; PENA, P. G. L. Feira livre e risco de contaminação alimentar: estudo de abordagem etnográfica em Santo Amaro, Bahia. Revista Bahiana de Saúde Pública, v. 35, n. 1, p. 112, 2011.

3. ALMEIDA, R. B. et al. Condições higiênico-sanitárias da comercialização de carnes em feiras livres de Paranatanema, PE. Alimentos e Nutrição, v. 22, n. 4, p. 585-592, 2011.

4. ALVES, R. R. N.; SILVA, C.C.; ALVES, H. N. Aspectos socioeconômicos do comércio de plantas e animais medicinais em áreas metropolitanas do Norte e Nordeste do Brasil. Revista de Biologia e Ciências da Terra, v.8, n.1, p. 181-189, 2008.

5. ARAÚJO, A.C. et al. Caracterização socioeconômico-cultural de raizeiros e procedimentos póscolheita de plantas medicinais comercializadas em Maceió, AL. Revista Brasileira de Plantas Medicinais, v. 11, n. 1, p. 81-91, 2009.

6. ARJONA, F. B. S.; MONTEZUMA, R.C.M. SILVA, I. M. Aspectos etnobotânicos e biogeografia de espécies medicinais e/ou rituais comercializadas no mercado de Madureira, RJ. Caminhos da Geografia, v. 8, n.23, p. 41-50, 2007.

7. BRASIL. MINISTÉRIO DAS MINAS E ENERGIA. Projeto de fontes de abastecimento por água subterrânea no Estado do Rio Grande do Norte: diagnóstico do Município de Currais Novos. Brasília, DF, 2005.

8. BRASIL. MINISTÉRIO DO DESENVOLVIMENTO SOCIAL E COMBATE À FOME. Feiras livres da agricultura familiar: roteiro de implantação 2007. Brasília, DF, 2007.

9. BRASIL. Agencia Nacional de Vigilância Sanitária. RDC $n^{\circ} 10$, de 9 de março de 2010. Dispõe sobre a notificação de drogas vegetais junto à Agencia Nacional de Vigilância Sanitária (ANVISA) e dá outras providências. Diário Oficial da União. Brasília, DF, 10/03/2010.

10. DANTAS, I. C. D.; GUIMARÃES, F. R. Perfil dos raizeiros que comercializam plantas medicinais no município de Campina Grande, PB. Revista de Biologia e Ciências da Terra, v. 6, n. 1, p. 3944, 2006.

11. GORBERT, S.; FRIDMAN, S. A. Mercados no Rio de janeiro: 1834-1962. Rio de Janeiro: Codice, 2003.

12. IDEMA. Atlas para a Promoção do Desenvolvimento Sustentável no Rio Grande do Norte: Módulo II Região do Seridó (zonas Homogêneas de Caicó, Currais Novos e Serras Centrais. Natal: Opção Gráfica Editora, 2009. 186 p. 
13. IDU, M.; EHARBOR, J. O.; IDELE, S.O. Microbial load in some medicinal plants sold in local markets of Benin city, Nigeria. International Journal of Medicinal and Aromatic Plants, v. 1, n. 3, 2011.

14. INSTITUTO BRASILEIRO DE GEOGRAFIA E ESTATÍSTICA. (2013a). Sinopse do Censo Demográfico 2010: Rio Grande do Norte. IBGE. Disponível em:<http://www.censo2010.ibge.gov.br/sinopse/index.php?uf=24\&dados=1. Acesso em: 1 jun. 2013.

15. INSTITUTO BRASILEIRO DE GEOGRAFIA E ESTATÍSTICA. (2013b). Mapas escolares. IBGE. Disponível em: <http://mapas.ibge.gov.br/escolares>. Acesso em 15 fev 2013.

16. LIMA, P. G. C.; COELHO-FERREIRA, M.; OLIVEIRA, R. Plantas medicinais em feiras e mercados públicos do distrito florestal sustentável da BR 163, estado do Pará, Brasil. Acta Botanica Brasilica. Brasília, v. 25, n.2, 2011.

17. LUZ, M. T. Cultura contemporânea e medicinas alternativas: novos paradigmas em saúde no fim do século XX. PHYSYS: Revista de Saúde Coletiva. v.15, p. 145-176, 2005.

18. MEDEIROS, F.G.M. et al. Comparação da qualidade sanitária de amostras de Peumus boldus Molina industrializadas e artesanais do município de Currais Novos, RN. Holos. v. 3, p. 41-46, 2012.

19. MINNAERT, A. C. S. T.; FREITAS, M. C. S. Práticas de higiene em uma feira livre da cidade de Salvador (BA). Ciência \& Saúde Coletiva, n. 15, p. 1607-1614, 2010.

20. MONTEIRO, J. M. etal. Local markets and medicinal plant Commerce: a review with emphasis on Brazil. Economic Botany, v.64, n.4, 2010.

21. PAULINO, R. C. et al. Medicinal plants at the Sitio do Gois, Apodi, Rio Grande do Norte, Brazil. Revista Brasileira de Farmacognosia, v.22, n.1, p. 29-39, 2012.

22. PIRENNE, H. Economic and Social History of Medieval Europe. New York: A Harvest Book. 252 p. 1956.

23. PLESIS-STOMAN, D. et al. Traditional herbal medicines: potential degradation of sterols and sterolins by microbial contaminants. South African Journal of Science, v. 105, p. 147-150, 2009.

24. ROCHA, F. A. G.; SILVA, J. L. A.; CHAGAS, A. B. Avaliação do grau de contaminação microbiológica em plantas medicinais comercializadas no município de Currais Novos/RN resultados preliminares. In: V Congresso de Iniciação Científica - CONGIC. Natal, RN: CEFET, 2008. ISBN - 978-85-89571-42-5

25. ROCHA, F. A. G.; MEDEIROS, F. G. M.; SILVA, J. L. A Diagnóstico da qualidade sanitária de plantas medicinais comercializadas no município de Currais Novos, RN. HOLOS, ano 26, v. 2. 2010.

26. ROCHA, F. A. G. et al. Comércio informal de plantas medicinais: características da comercialização, crenças no uso e perfil socioeconômico dos feirantes de Lagoa Nova, RN. In: CONNEPI - Congresso Norte e Nordeste de Pesquisa e Inovação, 7., 2012, Palmas. Anais Ciência Tecnologia e inovação: ações sustentáveis para o desenvolvimento regional. Palmas: Editora do IFTO. ISBN 978-85-62830-10-5 Disponível em:<http://propi.ifto.edu.br/ocs/index.php/connepi/vii/paper/view/1995>. Acesso em: 17 mai. 2013. 
27. SANTOS, M.O espaço dividido: os dois circuitos da economia urbana dos países subdesenvolvidos. São Paulo: EDUSP, 2 ed. 2004433 p.

28. SATO, L. Processos cotidianos de organização do trabalho na feira livre. Psicologia e Sociedade, v.19, n.1, p. 95-102, 2007.

29. STATSOFT, Inc. STATISTICA (Data Analysis Software System), version 10. www.statsoft.com. 2010.

30. STEVIC, T. et al. Pathogenic microorganisms of medicinal herbal drugs. Archives of Biological Sciences, v. 64, n. 1, p. 49-58, 2012.

31. SUREKHA, D. et al. A review on role of quality control and quality assurance system in regulation of herbal drugs. International Journal of Review in Life Sciences. v. 3, p. 97-105, 2011. 